\title{
Complications and outcomes of surgery for degenerative lumbar deformity in elderly patients
}

\author{
This article was published in the following Dove Press journal: \\ Orthopedic Research and Reviews \\ 24 December 2013 \\ Number of times this article has been viewed
}

\section{Hyo Jong Kim \\ Kyu Yeol Lee \\ Lih Wang}

Department of Orthopaedic Surgery, College of Medicine, Dong-A

University, Busan, Korea
Correspondence: Lih Wang

Department of Orthopaedic Surgery,

College of Medicine, Dong-A University,

3Ga-I, Dongdaesin-Dong, Seo-Gu,

Busan 602-715, South Korea

Tel +825 I2402593

Fax +825 I254 6757

Email libi33@dau.ac.kr
Background: The purpose of this study was to analyze the complications, clinical outcomes, and any correlative risk factors associated with degenerative lumbar deformity surgery in elderly patients.

Methods: We reviewed 78 patients who underwent posterior decompression and posterolateral fusion requiring a minimum three-level fusion for degenerative lumbar deformity associated with spinal stenosis between May 2001 and May 2006, with at least a one-year follow-up period. We assessed and compared the postoperative complications and clinical outcomes for patients aged 65 years and over (group A) and patients aged 50-64 years (group B). Risk factors that could influence complications and clinical outcome were evaluated and statistically analyzed.

Results: The postoperative complication rate was not significantly different between the two age groups (53\% in group A and 40\% in group B); however, group A had a significantly higher frequency of minor complications than group B, especially for urinary retention and postoperative delirium. A statistical relationship between diabetes mellitus and deep wound infection, one of the major complications of degenerative lumbar deformity surgery, was observed in both group A and group B. Male sex was a risk factor for urinary retention and long operative time, and abundant blood loss was a significant risk factor for postoperative delirium in group A.

Conclusion: There were no significant differences in results for degenerative lumbar deformity surgery between patients older and younger than 65 years. However, diabetes mellitus showed a significant correlation with deep wound infection, which is one of the major complications of degenerative lumbar deformity surgery, and with urinary retention and postoperative delirium, which occurred frequently in patients aged older than 65 years.

Keywords: spinal stenosis, lumbar deformity, elderly, risk factor, complication, clinical outcome

\section{Introduction}

Degenerative lumbar diseases are becoming more common due to the increasing elderly population. Fortunately, operative treatment intended to improve quality of life for patients with this condition is also increasing. ${ }^{1,2}$ Whereas several authors report good treatment results in elderly patients based on active operative treatments, ${ }^{3}$ most authors still recommend nonoperative treatments due to the risk of complications after major surgery. ${ }^{4,5}$

Degenerative lumbar deformity usually occurs after the age of 50 years and sometimes requires surgical treatment because symptoms worsen with advancing age. In particular, degenerative lumbar deformity surgery is the preferred treatment for patients older than 65 years; for patients who are considered to be at high risk because of other conditions, and often complain of persistent pain with conservative treatment. 
The purpose of this retrospective study was to compare the complication rates and outcomes after treatment with posterior decompression and long-segment fusion for degenerative lumbar deformity between patients older and younger than 65 years, in an effort to reduce the frequency of complications and improve clinical outcomes.

\section{Materials and methods}

The subjects in this study comprised 40 patients aged 65 years or older with degenerative lumbar deformity accompanied by spinal stenosis (group A). The patients had received conservative treatment for at least 3 months, but did not respond, so were provided with operative treatment, such as posterior decompression, instrumentation, and posterolateral fusion between May 2001 and May 2006. The patients were followed up for at least one year and were compared with 38 further patients in the age group of 50-64 years who had the same disease and were treated with the same methods (group B). The average age in group A was 75.6 (66-84) years and that in group B was 57.2 (51-64) years. The average duration of follow-up was $3.6(1-8)$ years.

Preoperative patient comorbidities included hypertension, diabetes mellitus, asthma, thyroid disease, and rheumatoid arthritis. Patients who had a history of preoperative accompanying diseases, according to this criterion, such as myocardial infarction and renal failure, were excluded from the study. All preoperative comorbidities were treated before surgery using appropriate medication, or else maintained in a state that would not prevent surgery.

In order to investigate surgery-related complications, short-term complications appearing 4 weeks after surgery were divided into two groups: major complications, including neurologic deficit, deep wound infection, pneumonia, pulmonary embolism, acute myocardial infarction, and acute renal failure; and minor complications, including superficial wound infections, ileus, acute gastritis, urinary tract infection, urinary retention, and postoperative delirium.

Clinical outcome was evaluated on the basis of existence and degree of lumbar and lower extremity pain and degree of postoperative activity. These evaluations were carried out using the clinical outcome measurement method suggested by Ragab et al, ${ }^{6}$ ie, based on the necessity for medication to control pain.

Postoperative complications and clinical outcomes in group A were compared with those in group B in terms of relevant risk factors. Sex, preoperative diagnosis, preoperative comorbidities, level of fusion, operative time, blood loss, and transfusion amount were examined, and their correla- tions with complications and outcomes were statistically analyzed.

The statistical analysis was performed using Statistical Package for the Social Sciences software version 12 (SPSS Inc, Chicago, IL, USA). Significant differences between groups and between variables were identified by $t$-tests for group comparison and chi-square tests for risk factor analysis.

\section{Results}

A total of 21 patients in each group, representing 53\% and $55 \%$ of group A and group B, respectively, had one or more preoperative comorbidities. Hypertension was the most common comorbidity in both groups, and diabetes mellitus was relatively more common in group B (Table 1). However, there was no significant difference between the two groups in terms of sex, preoperative diagnosis, comorbidities, fusion level, operative time, blood loss, transfusion amount, complications (except minor ones), or clinical outcome (Table 2).

The frequency of complications was higher in group A. The number of cases in which complications occurred was 21 in group A (53\%) and 15 in group B (40\%), although the difference was not statistically significant $(P=0.249)$. The number of cases in which major complications occurred was seven (18\%) and nine (24\%), respectively; so a relatively higher number occurred in group B, but again, the difference was not statistically significant $(P=0.499)$. However, the number of minor complications that occurred was 18 (45\%) and nine (24\%), respectively; thus, the number was larger in group A and the difference was statistically significant $(P=0.040)$. For the minor complications, urinary retention and postoperative delirium were significantly more frequent in group A than in group $\mathrm{B}(P=0.031$ and $P=0.033$, Table 3$)$.

Regarding clinical outcomes in group A and group B, the outcome was excellent in one (3\%) and three $(8 \%)$, respectively, good in 23 (58\%) and 26 (68\%), fair in $15(38 \%)$ and eight $(21 \%)$, and poor in one patient in each group

Table I Detail analysis of patient comorbidities between group A and group $B$

\begin{tabular}{llll}
\hline & $\begin{array}{l}\text { Group A } \\
(\mathbf{N} *=40)\end{array}$ & $\begin{array}{l}\text { Group B } \\
(\mathbf{N}=38)\end{array}$ & P-value \\
\hline Hypertension & I $7(42.5 \%)$ & II $(28.9 \%)$ & $0.2 \mathrm{I} 2$ \\
Diabetes mellitus & $5(\mathrm{I} 2.5 \%)$ & $9(23.7 \%)$ & 0.198 \\
Asthma & $\mathrm{I}(2.5 \%)$ & $\mathrm{I}(2.6 \%)$ & 1.000 \\
Thyroid disease & $\mathrm{I}(2.5 \%)$ & $2(5.3 \%)$ & 0.610 \\
Rheumatoid arthritis & $\mathrm{I}(2.5 \%)$ & $2(5.3 \%)$ & 0.610 \\
Total $(\mathrm{n} * *)$ & $25(\mathrm{~N}=2 \mathrm{I})$ & $25(\mathrm{~N}=2 \mathrm{I})$ & 0.807 \\
\hline
\end{tabular}

Notes: ${ }^{*} \mathrm{~N}$, number of patients; ${ }^{* *} \mathrm{n}$, number of cases. 
Table 2 Comparative analysis between group $A$ and group $B$

\begin{tabular}{|c|c|c|c|}
\hline & $\begin{array}{l}\text { Group A } \\
\left(N^{*}=40\right)\end{array}$ & $\begin{array}{l}\text { Group B } \\
(\mathrm{N}=38)\end{array}$ & $P$-value \\
\hline \multicolumn{4}{|l|}{ Sex } \\
\hline Male & $10(25.0 \%)$ & $5(13.2 \%)$ & 0.185 \\
\hline Female & 30 (75.0\%) & $33(86.8 \%)$ & \\
\hline \multicolumn{4}{|l|}{ Preoperative diagnosis } \\
\hline DLS & 29 (72.5\%) & $28(73.7 \%)$ & 0.696 \\
\hline LDK & $6(15.0 \%)$ & $5(13.2 \%)$ & \\
\hline DLS + LDK & I (2.5\%) & $3(7.9 \%)$ & \\
\hline $\begin{array}{l}\text { Postsurgical } \\
\text { scoliosis }\end{array}$ & $2(5.0 \%)$ & $0(0.0 \%)$ & \\
\hline $\begin{array}{l}\text { Postlaminectomy } \\
\text { kyphosis }\end{array}$ & $2(5.0 \%)$ & $2(5.3 \%)$ & \\
\hline $\begin{array}{l}\text { Existence of } \\
\text { comorbidity }\end{array}$ & 21 (52.5\%) & 21 (55.3\%) & 0.807 \\
\hline $\begin{array}{l}\text { Average fusion level } \\
\left(n^{* *}\right)\end{array}$ & $3.65 \pm 0.864$ & $3.74 \pm 0.921$ & 0.922 \\
\hline $\begin{array}{l}\text { Average operative } \\
\text { time (minutes) }\end{array}$ & $151.00 \pm 39.210$ & $156.05 \pm 29.550$ & 0.521 \\
\hline $\begin{array}{l}\text { Average blood loss } \\
(\mathrm{mL})\end{array}$ & $|, 372.50 \pm 646.88|$ & $\mathrm{I}, 660.53 \pm 755.98 \mathrm{I}$ & 0.373 \\
\hline $\begin{array}{l}\text { Average transfusion } \\
(\mathrm{mL})\end{array}$ & $1,229.75 \pm 706.760$ & $\mathrm{I}, 458.42 \pm 746.924$ & 0.216 \\
\hline Complication & 21 (52.5\%) & 15 (39.5\%) & 0.249 \\
\hline Major & $7(17.5 \%)$ & 9 (23.7\%) & 0.499 \\
\hline Minor & I 8 (45.0\%) & 9 (23.7\%) & 0.040 \\
\hline \multicolumn{4}{|l|}{ Clinical outcome } \\
\hline Excellent & I (2.5\%) & $3(7.9 \%)$ & 0.324 \\
\hline Good & $23(57.5 \%)$ & $26(68.4 \%)$ & \\
\hline Fair & 15 (37.5\%) & 8 (2I.1\%) & \\
\hline Poor & I $(2.5 \%)$ & I $(2.6 \%)$ & \\
\hline
\end{tabular}

Notes: *N, number of patients; **n, number of fusion levels.

Abbreviations: DLS, degenerative lumbar scoliosis; LDK, lumbar degenerative kyphosis.

(3\% versus $3 \%$ ). Clinical outcomes were not significantly different between the two groups ( $P=0.324$, Table 1$)$.

In the analyses of risk factors for complications and clinical outcome, diabetes mellitus showed a significant correlation with occurrence of deep wound infection in group A and group $\mathrm{B}(P=0.001$ and $P=0.035$, respectively). Male patients in group A developed urinary retention significantly more often $(P=0.01)$, and long surgical times and excessive blood loss showed a significant correlation with postoperative delirium ( $P=0.034$ and $P=0.001$, respectively). However, no other correlations between complications or clinical outcomes and other risk factors were evident.

\section{Discussion}

Degenerative lumbar deformities occur in the coronal and sagittal planes. Representative examples include degenerative lumbar scoliosis and degenerative lumbar kyphosis, and their frequencies are steadily increasing along with the increase in
Table 3 Detailed analysis of postoperative complications in group $A$ and group $B$

\begin{tabular}{|c|c|c|c|}
\hline & $\begin{array}{l}\text { Group A } \\
\left(N^{*}=40\right)\end{array}$ & $\begin{array}{l}\text { Group B } \\
(\mathrm{N}=38)\end{array}$ & $P$-value \\
\hline Major complications $\left(\mathrm{n}^{* *}\right)$ & $7(\mathrm{~N}=7)$ & $9(\mathrm{~N}=9)$ & 0.499 \\
\hline Neurologic deficit & 0 & 0 & - \\
\hline Deep wound infection & $3(7.5 \%)$ & $4(10.5 \%)$ & 0.708 \\
\hline Pneumonia & $2(5.0 \%)$ & $3(7.9 \%)$ & 1.000 \\
\hline Pulmonary embolism & I (2.5\%) & I (2.6\%) & 1.000 \\
\hline Acute myocardial infarction & $0(0.0 \%)$ & I (2.5\%) & 1.000 \\
\hline Acute renal failure & I (2.6\%) & $0(0.0 \%)$ & 0.487 \\
\hline Minor complications (n) & $22(\mathrm{~N}=18)$ & $9(\mathrm{~N}=9)$ & 0.040 \\
\hline Superficial wound infection & I (2.5\%) & I (2.6\%) & 1.000 \\
\hline lleus & I (2.5\%) & $2(5.3 \%)$ & 0.610 \\
\hline Acute gastritis & $4(10.0 \%)$ & $3(7.9 \%)$ & 1.000 \\
\hline Urinary tract infection & $4(10.0 \%)$ & $2(5.3 \%)$ & 0.676 \\
\hline Urinary retention & 5 (I2.5\%) & $0(0.0 \%)$ & 0.031 \\
\hline Postoperative delirium & 7 (17.5\%) & I (2.6\%) & 0.033 \\
\hline Total $(n)$ & $29(\mathrm{~N}=2 \mathrm{I})$ & $18(\mathrm{~N}=15)$ & 0.249 \\
\hline
\end{tabular}

Notes: $* \mathrm{~N}$, number of patients; **n, number of cases.

the elderly population. However, these conditions cannot be treated easily because patients often hold many accompanying diseases and require long-segment fusions. Accordingly, the risk of complications also increases. ${ }^{5,7}$ According to several reports, in the case of degenerative lumbar scoliosis, the rate of complications is relatively high, ranging from $20 \%$ to $80 \% .^{5,8-10}$ The reported frequency of complications in elderly patients varies from author to author. For example, Daubs et $\mathrm{al}^{7}$ reported a complication rate of $37 \%$ after spinal deformity surgery in elderly patients aged 60 years and older. Arinzon et $\mathrm{al}^{11}$ reported a postoperative complication rate of $41.3 \%$ in 179 patients aged $65-74$ years, and a rate of $46.7 \%$ in 104 patients aged 75 years or older. In our study, the complication rates in group A (aged 65 years or older) and in group B (aged 50-64 years) were 53\% and 40\%, respectively, and major complication rates were $18 \%$ and $24 \%$, respectively. Thus, major complications were more frequent in the younger age group, but not significantly so. Minor complication rates were $45 \%$ in group A, and $24 \%$ in group B, respectively, indicating that these occurred significantly more frequently in the older age group.

The reported correlation between complication rates and patient age also varies from author to author. Whereas Ragab et $\mathrm{al}^{6}$ reported that age does not affect the incidence of complications, Carreon et $\mathrm{al}^{5}$ and Deyo et $\mathrm{al}^{4}$ reported that complications would increase with age. Park et al ${ }^{12}$ reported that, although a statistically significant relationship was not found between age and overall complication rate, statistically significant differences were found between their elderly and nonelderly patients in terms of the incidence of major 
complications affecting the operative outcome. In our present study, differences between group A and group B, age with the incidences of complications and the major complications did not show statistically significant. However, the incidence of minor complications was significantly higher in group A. It is believed that significant differences appeared for minor complications but not for major complications in the group aged over 65 years because the criteria for selecting preoperative comorbidities and postoperative complications differ between investigators. In this study, patients who had a history of preoperative accompanying diseases according to this criterion of major complications, such as myocardial infarction and renal failure were excluded, and postoperative complications were defined as short-term complications appearing within 4 weeks after surgery.

With regard to the effect of preoperative comorbidities on the incidence of complications, Benz et $\mathrm{al}^{13}$ and Carreon et $\mathrm{al}^{5}$ reported that preoperative accompanying diseases, including diabetes mellitus, were not correlated with the incidence of postoperative complications. However, Oldridge et $\mathrm{al}^{14}$ reported that more preoperative comorbidities were associated with a higher incidence of complications, while Park et $\mathrm{al}^{12}$ reported that correlations between diabetes mellitus and major complications (eg, deep wound infection) were statistically significant in the older age groups. In this study, there was no difference between the two groups in terms of preoperative comorbidities and the incidence of complications. However, diabetes mellitus showed a significant correlation with deep wound infections, which was one of the major complications in group A and in group B. Furnary et $\mathrm{al}^{15}$ reported that the frequency of deep sternal wound infection after cardiac surgery was $2 \%$ in diabetic patients of average age 65 years subcutaneously injected with insulin. This frequency was reduced to $0.8 \%$ in groups intravenously injected with insulin throughout surgery. This suggests that the incidence of complications in diabetic patients can be reduced by strict blood sugar control during surgery.

However, in general, there are few reports in the literature concerning absolute values for preoperative, postoperative, or intraoperative blood sugar control in diabetic patients. Van den Berghe et $\mathrm{al}^{16}$ recommended maintaining blood sugar at a normal level (below $110 \mathrm{mg} / \mathrm{dL}$ ) when treating wounds in critically ill patients. However, this method involves the risk of low blood sugar, so Dellinger et $\mathrm{a}^{17}$ suggested it would be better to maintain blood sugar at a level below $150 \mathrm{mg} / \mathrm{dL}$. Further, Olsen et al ${ }^{18}$ emphasized that diabetes mellitus and high preoperative or postoperative blood sugar levels are risk factors for postoperative spinal infection. They suggested that preventive injections of antibiotics one hour prior to surgery and increased doses for obese patients could reduce the risk of infection. Therefore, it is thought that in order to reduce the risk of infection after spinal surgery, preoperative blood sugar should be maintained at the normal level or below $150 \mathrm{mg} / \mathrm{dL}$ if possible. Depending on the situation, additional antibiotics should be administered. Additional studies are necessary to confirm these findings.

Park et $\mathrm{l}^{12}$ reported that operative time and amount of transfusion were significantly related to the incidence of minor complications in both elderly groups and nonelderly groups. Cho et $\mathrm{al}^{19}$ reported that excessive blood loss during surgery for degenerative spinal scoliosis had a significant correlation with early complications. However, there was no risk factor that showed a significant correlation with later complications. In this study, in the case of male patients in group A, a significant number of cases with urinary retention, lengthy surgery, and excessive blood loss developed postoperative delirium. Postoperative urinary retention may be attributable to postoperative pain, the composite actions of general anesthesia and narcotic analgesics, or nerve injury. However, it is thought that the primary cause could be underlying disease resulting from old age. ${ }^{20}$ Especially in the case of older male patients where prostatic hyperplasia is common, it is reasonable to conduct a urologic examination before surgery. With regard to the delirium occurring after spinal surgery, Kawaguchi et $\mathrm{a}^{21}$ reported that this occurred more frequently in older patients and was associated with lowvolume values for hemoglobin and erythrocytes in blood tests on the first postoperative day. Therefore, it is thought that in order to reduce the incidence of postoperative delirium, a reduced operation time, complete bleeding control, additional blood transfusion, and identification of volume values for hemoglobin and erythrocytes by blood tests on the first postoperative day, is necessary depending on circumstances.

In an analysis of clinical outcomes of surgery for spinal deformity, Daubs et $\mathrm{al}^{7}$ compared the preoperative and postoperative Oswestry Disability Index and statistically analyzed the results. They found that significant recovery occurred, ie, a change in the score from 49 points preoperatively to 25 points postoperatively was evident. In our study, we used the method suggested by Ragab et $\mathrm{al}^{6}$ for measuring clinical outcome. This study of 78 cases of decompressive surgery with fusion for degenerative lumbar 
deformity associated with spinal stenosis in elderly patients demonstrated relatively favorable outcomes and satisfaction in this patient population. The clinical outcomes showed excellent or good results in $60 \%$ of group A and $76 \%$ of group B. Further consideration is needed regarding how to improve clinical outcomes in patient over 65 years of age, although the difference between the two age groups was not statistically significant. The authors recommend adequate conservative treatment for degenerative lumbar deformity prior to surgery, and careful consideration is necessary when selecting the operative treatment in this patient population because of their relatively high surgical risk. If operative treatment is selected, age does not change the outcome of lumbar deformity surgery in elderly patients, and the authors therefore do not use age as a criterion for offering surgical correction of the condition.

\section{Conclusion}

The surgical treatment outcomes for degenerative lumbar deformity accompanied by spinal stenosis in elderly patients aged 65 years or older did not show any significant difference from those in a group aged 50-64 years. Further, the outcomes for patients aged over 65 years did not indicate any significant increase in complications, except for minor ones. However, it is thought that in order to minimize the risk of deep wound infection after surgery, preoperative and postoperative blood sugar levels should be strictly controlled and additional antibiotics should be administered, depending on the clinical situation. It is considered that appropriate action should be taken to prevent urinary retention and postoperative delirium, which are common in older patients aged over 65 years.

\section{Acknowledgment}

The authors thank Dong-A University and Dong-A University Hospital for funding this clinical research. This paper was presented at the 2008 annual meeting of the Korean Society of Spine Surgery, Seoul, Korea.

\section{Disclosure}

The authors report no conflicts of interest.

\section{References}

1. Jonsson B, Stromqvist B. Lumbar spine surgery in the elderly. Complications and surgical results. Spine. 1994;19:1431-1435.

2. Sanderson PL, Wood PL. Surgery for lumbar spinal stenosis in old people. J Bone Joint Surg Br. 1993;75:393-397.

3. Yone K, Sakou T, Kawauchi Y, Yamaguchi M, Yanase M. Indication of fusion for lumbar spinal stenosis in elderly patients and its significance. Spine. 1996;21:242-248.

4. Deyo RA, Ciol MA, Cherkin DC, Loeser JD, Bigos SJ. Lumbar spinal fusion: a cohort study of complications, reoperations, and resource use in the Medicare population. Spine. 1993;18:1463-1470.

5. Carreon LY, Puno RM, Dimar JR II, Glassman SD, Johnson JR. Perioperative complications of posterior lumbar decompression and arthrodesis in older patients. J Bone Joint Surg Am. 2003;85:2089-2092.

6. Ragab AA, Fye MA, Bohlman HH. Surgery of the lumbar spine for spinal stenosis in 118 patients 70 years of age or older. Spine. 2003;28:348-353.

7. Daubs MD, Lenke LG, Cheh G, Stobbs G, Bridwell KH. Adult spinal deformity surgery. Spine. 2007;32:2238-2244.

8. Aebi M. The adult scoliosis. Eur Spine J. 2005;14:925-948.

9. Zurbriggen C, Markwalder TM, Wyss S. Long-term results in patients treated with posterior instrumentation and fusion for degenerative scoliosis of the lumbar spine. Acta Neurochir (Wien). 1999;141:21-26.

10. Marchesi DG, Aebi M. Pedicle fixation devices in the treatment of adult lumbar scoliosis. Spine. 1992;17:304-309.

11. Arinzon ZH, Fredman B, Zohar E, et al. Surgical management of spinal stenosis: a comparison of immediate and long term outcome in two geriatric patient populations. Arch Gerontol Geriatr. 2003;36:273-279.

12. Park HJ, Lee PE, Lee DK, Park HK. Postoperative complications in patients over 65 years of age with lumbar spinal stenosis and its influencing factors. J Korean Spine Surg. 2006;13:114-119.

13. Benz RJ, Ibrahim ZG, Afshar P, Garfin SR. Predicting complications in elderly patients undergoing lumbar decompression. Clin Orthop Relat Res. 2001;384:116-121.

14. Oldridge NB, Yuan Z, Stoll JE, Rimm AR. Lumbar spine surgery and mortality among Medicare beneficiaries. Am J Public Health. 1994;84:1292-1298.

15. Furnary AP, Zerr KJ, Grunkemeier GL, Starr A. Continuous intravenous insulin infusion reduces the incidence of deep sternal wound infection in diabetic patients after cardiac surgical procedures. Ann Thorac Surg. 1999;67:352-362.

16. Van den Berghe G, Wouters P, Weekers F, et al. Intensive insulin therapy in critically ill patients. N Engl J Med. 2001;345:1359-1367.

17. Dellinger RP, Carlet JM, Masur H, et al. Surviving sepsis campaign guidelines for management of severe sepsis and septic shock. Crit Care Med. 2004;32:858-873.

18. Olsen MA, Nepple JJ, Riew KD, et al. Risk factors for surgical site infection following orthopaedic spinal operations. J Bone Joint Surg Am. 2008;90:62-69.

19. Cho KJ, Suk SI, Park SR, et al. Complications in posterior fusion and instrumentation for degenerative lumbar scoliosis. Spine. 2007;15: 1551-1554.

20. Selius BA, Subedi R. Urinary retention in adult: diagnosis and initial management. Am Fam Physician. 2008;77:643-650.

21. Kawaguchi Y, Kanamori M, Ishihara H, et al. Postoperative delirium in spine surgery. Spine. 2006;6:164-169.
Orthopedic Research and Reviews

\section{Publish your work in this journal}

Orthopedic Research and Reviews is an international, peer-reviewed, open access journal focusing on the patho-physiology of the musculoskeletal system, trauma, surgery and other corrective interventions to restore mobility and function. Advances in new technologies, materials, techniques and pharmacological agents are particularly welcome. The journal welcomes

\section{Dovepress}

original research, clinical studies, reviews \& evaluations, expert opinion and commentary, case reports and extended reports. The manuscript management system is completely online and includes a very quick and fair peer-review system, which is all easy to use. Visit http://www.dovepress. com/testimonials.php to read real quotes from published authors. 